\title{
An Assessment on Graham's Approach for Stock Selection: The Case of Turkey
}

\author{
Nuray Terzi ${ }^{1}$ \\ ${ }^{1}$ Department of Economics, Marmara University, Istanbul, Turkey \\ Correspondence: Nuray Terzi, Goztepe Kampusu 34722 Kuyubası Goztepe, Istanbul, Turkey. Tel: \\ 216-541-4021-1517.
}

Received: October 21, 2015

Accepted: November 14, $2015 \quad$ Online Published: December 4, 2015

doi:10.5430/ijfr.v7n1p50

URL: http://dx.doi.org/10.5430/ijfr.v7n1p50

\begin{abstract}
Graham's approach is widely discussed by individual investors, portfolio managers and academicians in these days. Graham's approach has very simple formula to evaluate the company's intrinsic value. The fundamental idea behind the concept is the opinion that companies have an intrinsic value which the markets don't necessary reflect in their stock prices. Intrinsic value is defined by a company's asset, dividend, earning and financial ability. To focus on this value can hinder an investor from wrong decision especially, uncertainty times. In this perspective, this study aims to investigate the performance of stock selection criteria of Benjamin Graham on Istanbul Stock Exchange for the period from 2005 to 2014. The results showed that an investors who used Benjamin Graham's criteria, would have achieved better results than that of the BIST-100 in between 2005 and 2014, excluded crisis period. Further research can be conducted with different criteria in other developing countries.
\end{abstract}

Keywords: intrinsic value, stock selection criteria, Benjamin Graham, Istanbul Stock Exchange

\section{Introduction}

The concept of value investing is broadly used by portfolio managers and investors as an investing approach nowadays. This approach was fundamentally created in 1934 by with the publishing of Benjamin Graham and Dodd's book "Security Analysis." He is widely known as one of the "fathers" of value investing. Graham's view based on the notion of an intrinsic value that is defined by a company's asset, dividend, earning and financial ability. Scott (1996) informed that to focus on this value would hinder an investor from wrong decision during periods of uncertainty times.

Benjamin Graham believed that stock markets are not efficient. Graham \& Zweig (2003) proposed that not overpaying for a stock is one of the safest methods which can be used in investments. Therefore, excess returns can be had without significant risks through an investment paradigm called value investing. Value investing as defined by Graham \& Zweig (2003) is based on three characteristics of the financial markets. Firstly, the prices of financial securities are subject to irregular and significant movements. Secondly, despite these irregular movements, financial securities have quite stable underlying values. Finally, the time to buy financial securities is when they are selling significantly below their intrinsic value or what they are really worth based on assets of the company. Buying financial securities that have a market price below their intrinsic value provides safety for the value investor in the shape of not over-paying for what those securities are worth.

Studies showed that although Benjamin Graham's stock selection criteria have been conceived many years ago, Benjamin Graham's criteria is applicable and useful in the several markets, such as London Stock Exchange, Johannesburg Stock Exchange, Malaysian market and Indian market for the specific periods. These studies informed that the using of Benjamin Graham's stock selection criteria propagates return in those markets.

Whether using the Graham's stock selection criteria is able to produce higher return than the market return in Istanbul Stock Exchange represents the main motivation for this study. Additionally, the study is different from the previous studies in the sense that the study implements Graham's stock selection criteria in Turkey's stock market for the first time. 
Therefore, this study aims to examine the performance of stock selection criteria of Benjamin Graham on Istanbul Stock Exchange for the period 2005 to 2014. In order to achieve this, following section will focus theoretical background. Third section will explain data and methodology and finally, it will be given the results and conclusion.

\section{Theoretical Background}

Graham pointed out that it would be hard for investors to reach stocks that will make better average than long term market average. Stocks will have better performance than average over the long term is those with higher growth, but the problem is finding those beforehand. Graham indicated that there are two problems for investors. First, although stocks with clear progress possibility don't turn into more profits for an investor, these possibilities are adjoined into the stock prices. Second, there is a risk that financiers will be inaccurate about the company's progress view. Graham believed that risks are underlined by stock market situation and this could misdirect investors into undervaluing or overvaluing a stock. In place of looking a way to produce over-average returns, Graham suggested a technique to mitigate the risk of wrong decision. Therefore, Graham recommended that investors think an intrinsic value for a stock. Actually, Benjamin Graham didn't exactly clarified how to identify intrinsic value. However, he thought that a company's physical properties were an important factor; other factors included dividends, earnings, financial ability, and financial stability (Scott, 1996).

Graham also defined that investors are classified into the two groups: defensive and aggressive investors (Oppenheimer and Schlarbaum, 1981). Graham contained in the defensive investor group professionals who are unable to dedicate much time to the transaction and young investors who are unfamiliar and inexperienced with in financial markets. Aggressive investors who has time, interest and knowledge to find specific stocks and they are also comfortable with high momentum stocks.

Graham (1973) presents specific rules for defensive investors. These rules are about adequate size, financial condition, earnings stability, dividend record, earning growth, moderate price to earnings ratio and price to book value. Graham recommended that size of the company should not be less than $\$ 100$ million of annual sales and, not less than $\$ 50$ million of total assets for a public one. For strong financial condition in industrial companies, current assets should be at least twice current liabilities. There should be some earnings for the common stock in each of the past ten years for stability. For dividend record, there should be uninterrupted payments for at the least the past 20 years. For earnings growth, there should be a minimum increase of the at least one-third in per-share earnings in the past ten years. Finally, current price should not be more than 15 times average earnings of the past three years and should not be more than $1 \frac{1}{2}$ times the book value recent recorded.

Graham also proposed some criteria for aggressive investors (Graham, 1973). Such as, for size, it can be selected from a broaden environment of stocks. For strong financial condition, assets should be at least $1 \frac{1}{2}$ times current liabilities. There should be some level of dividend payments for strong dividend payment. For the ratio of price-to-book-value, prices should be less than $120 \%$ of net physical assets.

There are several studies which are based on Benjamin Graham's stock selection criteria. These studies have found considerable premium provided by these principles for example, Oppenheimer and Schlarbaum, (1981), Klerck and Maritz (1997), Xiao and Arnold (2008), Balik and Mehran (2008), Chang (2011) and Singh and Kaur (2014).

Oppenheimer and Schlarbaum (1981) used the Benjamin Graham's stock selection criteria to identify stocks and applied them for the period December 1955 and December 1975. In their study, the performance measure was Jensen's alpha. They found that the alpha values are positive.

Klerk and Maritz (1997) indicated investors who used of the composition of Benjamin Graham's stock criteria to constitute a portfolio, would have provided better outcome than the Index on the Johannesburg Stock Exchange for the period 1977 to 1994.

Xiao and Arnold (2008) applied by Benjamin Graham criteria to determine if it is still applicable and they used stocks listed on Stock Exchange in London between 1981 and 2005. They found that the using this has produced higher return than the market.

Balik and Mehran (2008) tested Graham methodology for 2000 and previous years. They found that using Benjamin Graham's defensive investor criteria met nine stocks. Although the calculated alpha for this portfolio was negative, it is statistically significant.

Chang (2011) aimed to determine if the use of some of Graham's stock selection criteria is able to create returns that are significantly better returns than the market returns in Malaysia Stock Exchange. Chang collected secondary data regarding fundamentals of companies listed in the FTSE Bursa Malaysia EMAS Index for the year 2000 to 2009. 
The study found that most of the screening criteria used generated returns that were higher than the market return in almost every year which were tested in.

Singh and Kaur (2014) showed that the stocks that meet any four rules of Graham's stock selection criteria can significantly provide more returns to investors if they hold such a portfolio for 24 months.

\section{Data and Methodology}

In this research, universe of the study comprises of the stocks listed at Istanbul Stock Exchange. The data were both provided and analyzed by Queen Stocks Professional Program. The study is conducted over the period of nine years that is 2005-2014. In the first stage of study, it was selected the stocks as modified Graham criteria. Secondly, the portfolio performance was calculated by using analytical tools. Finally, the portfolio performance was compared by an index performance.

Following criteria are applied simultaneously, and used as strains in order to identify which stocks are included or excluded. The stock selection rules of Benjamin Graham have been considered quite stringent by the researchers who consider that if all the rules of Graham are simultaneously applied on the stocks, no stocks will qualify for the portfolio (Scott, 1996; Klerk and Maritz, 1997). Therefore, during the portfolio selection, some of criteria are modified due to the fact that the criteria are quite stringent. If they are applied in the same time, no stocks satisfy for a portfolio.

Following criteria were applied:

$\checkmark$ Adequate size: The size of the companies was more than 300 million Turkish Liras of annual sales for a company.

$\checkmark \quad$ Strong financial condition: Current ratio was more than two.

$\checkmark$ Earnings stability: Net profit was more than zero for the stock in each of the past five years.

$\checkmark \quad$ Strong dividend record: Dividend record was more than zero.

$\checkmark$ Earnings growth: Net profit was more than five years earlier net profit.

$\checkmark$ Moderate price earnings ratio: Current prices (price -earnings ratio) were less than 15 times average earnings of the last year.

$\checkmark$ Moderate the ratio of price to book value: Current prices were less than $1 \frac{1}{2}$ times the book value last recorded.

In order to analyze the performance and risk of stocks arrived at after meeting different criteria, it was used of following analytical tools (Table 1), and BIST-100 index of Istanbul Stock Exchange has been used as a benchmark to compare the performance of Graham portfolio.

Table 1. Analytical tools and their description and interpretation

\begin{tabular}{|c|c|c|}
\hline Measures & Description & Interpretation \\
\hline Sharpe Ratio & $\begin{array}{l}\text { Sharpe Ratio }=(\mathrm{R} p-\mathrm{R} f) / \sigma p \\
\mathrm{R} p=\text { Return of } \mathrm{p} \text { portfolio, } \\
\mathrm{R} f=\text { Risk Free Rate, } \\
\sigma p=\text { Standard deviation of return of } \mathrm{p} \\
\text { portfolio. }\end{array}$ & $\begin{array}{l}\text { The higher Sharpe } \\
\text { ratio means better a } \\
\text { fund returns. }\end{array}$ \\
\hline Treynor Ratio & $\begin{array}{l}\text { Treynor Ratio }=(\mathrm{Rp}-\mathrm{Rf}) \beta \mathrm{p} \\
\mathrm{R} p=\text { The expected return of portfolio } \mathrm{P}, \\
\mathrm{R} f=\text { Risk Free Rate, } \\
\beta p=\text { Beta coefficient of portfolio } \mathrm{P} .\end{array}$ & $\begin{array}{l}\text { The higher Treynor } \\
\text { ratio means better } \\
\text { returns. }\end{array}$ \\
\hline Jensen Alfa & $\begin{array}{l}\alpha=\mathrm{Rp}-[\mathrm{Rf}+\beta \mathrm{p}(\mathrm{Rm}-\mathrm{Rf})] \\
\mathrm{R} p=\text { The expected return of portfolio } \mathrm{P} \\
\mathrm{R} f=\text { Risk Free Rate, }\end{array}$ & $\begin{array}{l}\text { Jensen Alfa is based } \\
\text { on systematic risk. }\end{array}$ \\
\hline
\end{tabular}




\begin{tabular}{|c|c|c|}
\hline & $\begin{array}{l}\beta p=\text { Beta coefficient of portfolio } \mathrm{P} . \\
\mathrm{Rm}=\text { Market return }\end{array}$ & \\
\hline Standard Deviation & $\begin{array}{l}\text { Standard Deviation evaluates the volatility } \\
\text { of the fund. }\end{array}$ & $\begin{array}{l}\text { It should be near to } \\
\text { its mean return }\end{array}$ \\
\hline Beta & $\begin{array}{l}\text { Beta measures the level of volatility } \\
\text { associated with the fund as compared to the } \\
\text { benchmark fund. }\end{array}$ & $\begin{array}{l}\text { Beta }>1=\text { high risky } \\
\text { Beta }=1=\text { Avg } \\
\text { Beta }<1=\text { Low Risky }\end{array}$ \\
\hline Portfolio/Index Return & $\begin{array}{l}\mathrm{R} p=\mathrm{R} p t-\mathrm{R} i(\mathrm{t}-1) / \mathrm{R} i(\mathrm{t}-1) \\
\mathrm{R} p=\text { The expected return of portfolio } \mathrm{P} \\
\mathrm{R} p t=\text { Closing value at } \mathrm{t} \text { day } \\
\mathrm{R} i(\mathrm{t}-1)=\text { Closing value at }(\mathrm{t}-1) \text { day. }\end{array}$ & \\
\hline
\end{tabular}

\section{Results}

The first step of this study was to select the stocks by using the Graham criteria. According to results, a few companies passed the modified Graham criteria. The criteria allowed investment in less than BIST-100. Additionally, modified Graham criteria allowed investment different number companies in years. Table 2 gives the company name's which satisfy the criteria for each year, quarterly. The results show Graham criteria, although they were modified, quite stringent.

Table 2. Results of modified Graham criteria

\begin{tabular}{lllll}
\hline & I & II & III & IV \\
\hline 2005 & AKSA, ANACM, & AKSA, ANACM, & ECZYT,SISE, & ECZYT \\
& BRISA, CIMSA, & BRISA, CIMSA, & TRKCM & \\
& ECZYT, SISE & ECZYT, SISE & & \\
2006 & - & - & BRISA,ECZYT & AKSA \\
2007 & ALARK,SODA & ALARK & - & BRISA,ECZYT \\
2008 & BRISA,ECILC & ASELS, & ASUZU, & ASUZU,ECILC,GOO \\
& ECZYT & ECILC,ECZYT & ECILC,ECZYT & DY \\
2009 & ASUZU, & AKSA, FROTO & - & - \\
& BAGFS,EREGL & & & \\
2010 & ALARK, ECILC, & ALARK, ECILC, & ECILC, & ECILC, \\
& ECZYT & ECZYT, VESBE & ECZYT,TRKCM,V & ECZYT,SISE,TRKCM \\
& & & ESBE & \\
2011 & SISE,TRKCM & ARCLK, SODA & SODA & ALARK,ECYZT,SISE \\
& & & & SODA, ÜLKER \\
2012 & ALARK, & ALARK, & SISE & ALARK, \\
& ECILC,ECZYT, & ECILC,ECZYT, & & ENKAI,SISE,SODA \\
& ENKAI,SISE,SODA & SISE, TRKCM & & SODA \\
2013 & SISE & - & - & GOLTS, \\
2014 & SISE,SODA & GOLTS, GOODY, GOLTS, & SISE, SODA,TRKCM \\
\hline
\end{tabular}

Secondly, the performances and risks of both Graham portfolio and BIST-100 was calculated by using Sharpe ratio, Treynor Ratio, Jensen alpha, Beta and Standart deviation. According to the application results, for the market 
portfolio, the measures of performance are negative for between 2005 and 2014. The performances of Graham portfolio are higher than the market's (Table 3).

Sharpe ratio measures risk-adjusted return of an investment. The result shows the return per unit of total risk. The greater a portfolio's Sharpe ratio means the better its risk-adjusted performance. Sharpe ratio for Graham portfolio was higher than BIST 100. It was 0.07 while BIST sharpe ratio was -0.10 .

Treynor ratio utilizes market risk instead of total risk. Similar to Sharpe Ratio, Treynor Ratio measures the efficiency utilizing the relation between risk-adjusted return and risk. High ratio gives better performance efficiency for the portfolio. Treynor ratio was positive for Graham portfolio. It was 0.97 . However, for BIST 100 Treynor ratio was -0.87. It was negative and smaller than Graham portfolio.

Jensen Alpha measures the average return on a portfolio and this is also the alpha of portfolio. If the value is positive, than the portfolio is earning excess returns. Jensen Alpha was positive and 1.23. Graham portfolio gained excess return.

Beta presents a measure of a portfolio's volatility. A beta of 1 means the security's price moves with the market price. A beta of more than 1 represents higher volatility while a beta of less than 1 represents lower volatility. Beta is an important component in financial models which use volatility and risk to estimate expected returns. Graham portfolio's beta has a beta of 0.64 which suggests that less risky than average market.

Standard deviation measures the volatility of investment. Standard deviation is also known as historical volatility and is applied by investors as an evaluation for the amount of anticipated volatility. A fund with a high return and a low standard deviation generally is concerned attractively. Portfolio standard deviation realized higher than market because of the less diversification.

Table 3. Results of performance and risk of Graham portfolio and BIST 100

\begin{tabular}{lcc}
\hline & \multicolumn{2}{c}{$2005-2014$ Cumulative } \\
& Graham Portfolio & BIST 100 \\
\hline Sharpe Ratio & 0.07 & -0.10 \\
Treynor Ratio & 0.97 & -0.87 \\
Jensen Alpha & 1.23 & \\
Beta & 0.64 & 1 \\
Standard Deviation & 8.50 & 8.36 \\
\hline
\end{tabular}

The Figure 1 shows Graham portfolio and BIST 100 index performance. As seen from the figure 1, the Graham portfolio grows from TL100,000 to TL 261.016 from January 2004 to December 2014 whereas the BIST 100 index goes from TL100,000 to TL 157,831. Graham portfolio provided more return than market. It was $68.45 \%$. However, the Graham portfolio formed in the period of March 2009 and July 2011 had a lower performance that of the market because of global financial crisis. 


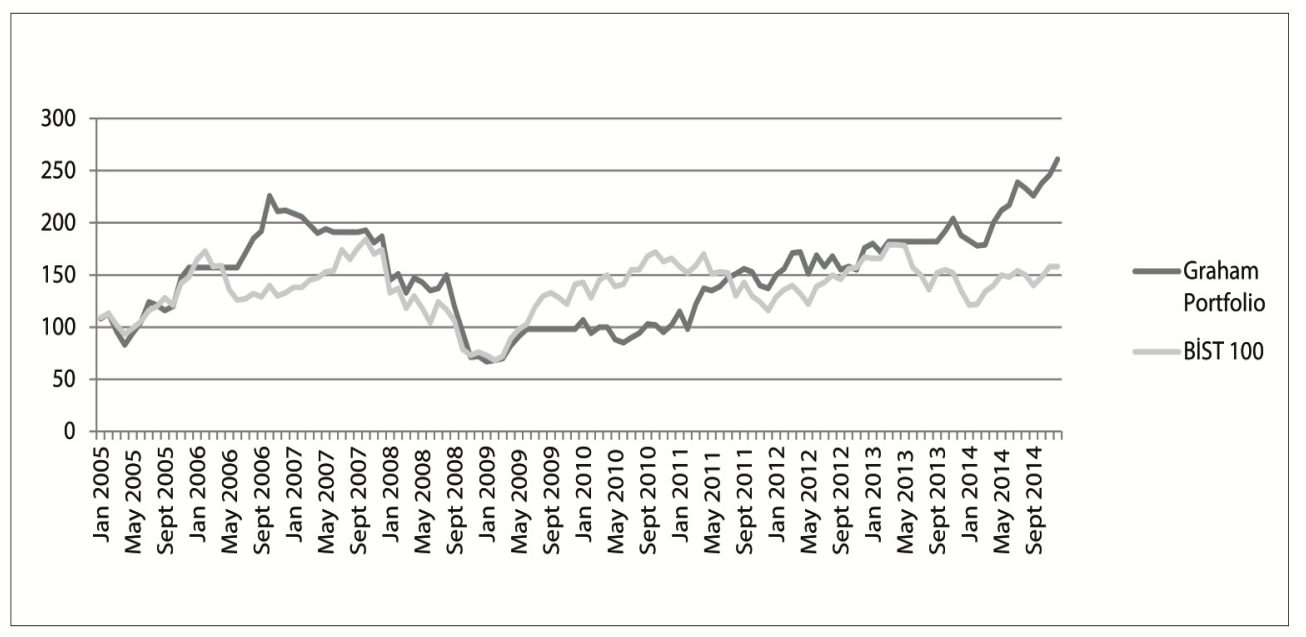

Figure 1. The value of TL 100.000 investments in Graham portfolio and BIST 100 index

Annual returns of the portfolio and index from 2005 to 2014 are shown in Table 4. Annual returns of Graham portfolio were higher than BIST 100 for five years $(2005,2006,2011,2013,2014)$.

Table 4. Annual returns

\begin{tabular}{lcc}
\hline & Graham Portfolio $\%$ & BIST $100 \%$ \\
\hline 2005 & 56.55 & 47.90 \\
2006 & 35.25 & -10.32 \\
2007 & -11.72 & 30.99 \\
2008 & -61.40 & -56.05 \\
2009 & 36.23 & 84.59 \\
2010 & 4.04 & 17.43 \\
2011 & 33.62 & -29.68 \\
2012 & 28.56 & 43.70 \\
2013 & 6.88 & -19.28 \\
2014 & 39.01 & 16.90 \\
\hline
\end{tabular}

\section{Conclusion}

This paper has mainly aimed to investigate the performance of stock selection criteria of Benjamin Graham on Istanbul Stock Exchange for the period from 2005 to 2014. Findings of this study indicate that an investor who used of the composition of these criteria to create a Graham's portfolio, would have provided better results than that of the BIST-100 during the period 2005 and 2014, excluded crisis period. This is a great advantageous for defensive investors that can satisfy basic company fundamentals. When considered in conjunction with market conditions, the criteria of stock selection of Graham can optimize the investment decision making. Future researches can be made to obtain the maximum possible return in Istanbul Stock Exchange.

The study also suggests that investors do not intend to invest in the stock market when the economy is turbulent. Except the financial crisis times, using of Graham's stock selection criteria is practical and functional to take advantageous. The criteria can produce greater return than the market return and stimulate the economy. 
Additionally, due to the Graham criteria are stringent, if they are modified it will give better results for developing markets. From this research, it can be seen that using of Graham's stock selection criteria is adequate to create preferable return than the market return. If it is used different combinations of Graham's stock selection criteria, better returns can be found in different markets.

\section{References}

Balik, R., \& Mehran, J. (2008). Benjamin Graham revisited. Retrieved from http://www.academyfinancial.org/09Conference/09Proceedings/(5D)\%20Balik,\%20Mehran.pdf

Chang, D. (2011). Testing some of Benjamin Graham's stock selection criteria: A case of the FTSE Bursa Malaysia EMAS Index from Year 2000 to 2009. Journal of Management and Entrepreneurship, 13(2), 99-106.

Graham, Benjamin. (1973). The Intelligent Investor, Revised Edition.

Graham, B., \& Zweig, J. (2003). The Intelligent Investor (Revised Edition). New York: Harper Business Essentials.

Klerck, W. G., \& Maritz, A. C. (1997). A test of Graham's stock selection criteria on industrial shares traded on JSE. Investment Analysts Journal, 45, 25-33.

Oppenheimer, H. R., \& Schlarbaum, G. G. (1981). Investing with Ben Graham: An Ex Ante Test of the efficient markets hypothesis. The Journal of Financial and Quantitative Analysis, 16(3), 341-360. http://dx.doi.org/10.2307/2330242

Scott, Maria Crowd. (1996, May). Value Investing: A Look at the Benjamin Graham Approach. Stock Analysis Workshop, 12-15.

Singh, Jaspal, \& Kiranpreet Kaur. (2014). Testing Ben Graham's Stock Selection Criteria in Indian Stock Market. Management and Labour Studies, 39(1), 43-62. Retrieved from http://mls.sagepub.com/content/39/1/43

Xiao, Y., \& Arnold, G. (2008). Testing Benjamin Graham's net current asset value strategy in London. The Journal of Investing, 17(4), 11-49. http://dx.doi.org/10.3905/JOI.2008.17.4.011 